\title{
Determination of Volatile Organic Compounds in Selected Strains of Cyanobacteria
}

\author{
Ivan Milovanović, ${ }^{1}$ Aleksandra Mišan, ${ }^{1}$ Jelica Simeunović, ${ }^{2}$ Dajana Kovač, ${ }^{2}$ \\ Dubravka Jambrec, ${ }^{1}$ and Anamarija Mandic ${ }^{1}$ \\ ${ }^{1}$ Institute of Food Technology, University of Novi Sad, Bulevar cara Lazara 1, 21000 Novi Sad, Serbia \\ ${ }^{2}$ Department of Biology and Ecology, Faculty of Sciences, University of Novi Sad, Trg Dositeja Obradovića 2, 21000 Novi Sad, Serbia
}

Correspondence should be addressed to Anamarija Mandić; anamarija.mandic@fins.uns.ac.rs

Received 7 December 2014; Revised 21 January 2015; Accepted 10 February 2015

Academic Editor: Tzortzis Nomikos

Copyright (C) 2015 Ivan Milovanović et al. This is an open access article distributed under the Creative Commons Attribution License, which permits unrestricted use, distribution, and reproduction in any medium, provided the original work is properly cited.

\begin{abstract}
Microalgal biomass can be used in creating various functional food and feed products, but certain species of microalgae and cyanobacteria are known to produce various compounds causing off-flavour. In this work, we investigated selected cyanobacterial strains of Spirulina, Anabaena, and Nostoc genera originating from Serbia, with the aim of determining the chemical profile of volatile organic compounds produced by these organisms. Additionally, the influence of nitrogen level during growth on the production of volatile compounds was investigated for Nostoc and Anabaena strains. In addition, multivariate techniques, namely, principal component analysis (PCA) and hierarchical cluster analysis (HCA), were used for making distinction among different microalgal strains. The results show that the main volatile compounds in these species are medium chain length alkanes, but other odorous compounds such as 2-methylisoborneol (0.51-4.48\%), 2-pentylfuran (0.72-8.98\%), $\beta$-cyclocitral ( $0.00-1.17 \%)$, and $\beta$ ionone (1.15-2.72\%) were also detected in the samples. Addition of nitrogen to growth medium was shown to negatively affect the production of 2-methylisoborneol, while geosmin was not detected in any of the analyzed samples, which indicates that the manipulation of growth conditions may be useful in reducing levels of some unwanted odor-causing components.
\end{abstract}

\section{Introduction}

Cyanobacteria (blue-green algae) among all microalgae represent some of the oldest living organisms and show great biological diversity $[1,2]$. This evolutionary and phylogenetic diversity also means a great diversity regarding the chemical composition of these organisms, which makes them very attractive for use as sources of a wide range of biomolecules [3]. Microalgae are important sources of commercially produced high-value molecules including carotenoids [4], longchain polyunsaturated fatty acids (PUFA), proteins $[5,6]$, and phycobilins [7-9]. The addition of microalgal biomass to food and feed products is an interesting option for providing nutritional supplementation with these biologically active compounds. Novel foods development requires selection of microalgal species with balanced nutritional profiles and proven health safety. The chemical composition of microalgae is often highly dependent on various environmental factors, such as temperature, salinity, illumination, $\mathrm{pH}$ value, mineral content, $\mathrm{CO}_{2}$ supply, population density, growth phase, and physiological status [10]. Beside many beneficial properties, microalgae also produce numerous volatile organic compounds which can cause musty, fishy, and mud-like odour. Blooms and scums of cyanobacteria can occur in various fresh and brackish water environments, causing musty odour and production of harmful toxins [11]. When microalgal biomass is added to food products, its odour and aroma can influence the sensory properties of the final products [12], and, in natural environment, it can also affect the sensory quality of the produced food (e.g., fish) [13].

In this work, we investigated selected strains of Spirulina, Anabaena, and Nostoc originating from Serbia, which were previously proven to be nontoxic under specified growing conditions [14]. As the investigated strains show a potential for incorporation in novel food products, being rich in proteins and PUFAs [15], the aim of this study was to 
determine the chemical profile of volatile organic compounds produced by these organisms. Influence of nitrogen level during growth on the production of volatile compounds was also investigated for Nostoc and Anabaena strains. The mentioned work was undertaken in order to assess the best potential species of microalgae for incorporation in functional food products regarding their volatile compounds profile, as well as to determine the optimal growth conditions for minimizing undesirable sensory properties. In addition, multivariate techniques, principal component analysis (PCA), and hierarchical cluster analysis (HCA) were used to test whether they can be employed for making distinction among different microalgal strains.

\section{Materials and Methods}

2.1. Chemicals. A mixture of $\mathrm{n}$-alkanes (Sigma-Aldrich, Germany) from n-octane (C8) to eicosane (C20) was used for calculation of retention indices (RI).

2.2. Samples. Samples of Spirulina platensis (labeled as S1 and S2), Nostoc spp. (labeled as 2S7B and 2S9B), and Anabaena spp. (labeled as C2 and C5) strains were obtained from the Department of Biology and Ecology at the Faculty of Sciences, University of Novi Sad. All of the investigated strains originated from Vojvodina region of Serbia [16]. Strains of the Nostoc and Anabaena genera were cultivated under laboratory conditions in synthetic mineral broth BG11, with $(+\mathrm{N})$ and without added nitrogen $(-\mathrm{N})$ [17] while Spirulina strains were cultivated in mineral SOT broth [18]. All the investigated cyanobacteria were cultivated as steady cultures in Erlenmeyer flasks at temperature of $22-24^{\circ} \mathrm{C}$ and under illumination by cool white fluorescent light $(50 \mu \mathrm{mol}$ photons $\mathrm{m}^{-2} \mathrm{~s}^{-1}$ ). Daily light regimen was set to 12 hours of light and 12 hours of darkness. After 25 days of cultivation, the strains were lyophilized to obtain the dry algal biomass for analyses and kept well sealed at $5^{\circ} \mathrm{C}$ until usage.

2.3. Headspace and GC-MS Analysis Procedure. Static headspace sampling was performed with the headspace sampler, CombiPAL System (CTC Analytics, Zwingen, Switzerland). A $2.5 \mathrm{~mL}$ headspace syringe for CombiPAL was used for the injection of $2 \mathrm{~mL}$ from the $10 \mathrm{~mL}$ headspace vials with $1 \mathrm{~g}$ of measured dry sample or $50 \mu \mathrm{L}$ of $\mathrm{n}$-alkane mixture. The autosampler conditions were set as follows: incubation temperature, $80^{\circ} \mathrm{C}$; incubation time, $10 \mathrm{~min}$; syringe temperature, $100^{\circ} \mathrm{C}$; agitator speed, $500 \mathrm{rpm}$; fill speed, $100 \mu \mathrm{L} / \mathrm{s}$; pullup delay, $1 \mathrm{~s}$; injection speed, $500 \mu \mathrm{L} / \mathrm{s}$; pre- and postinjection delay, $500 \mathrm{~ms}$; flush time, $10 \mathrm{~s}$. After each injection, carryover in the syringe was eliminated by automatic flush of the syringe with carrier gas.

Chromatographic separation was achieved by Agilent Technologies GC-MS Model 7890 A Series gas chromatograph coupled to $5975 \mathrm{C}$ mass selective detector. A HP $5 \mathrm{MS}$ (30 $\mathrm{m} \times 0.25 \mathrm{~mm}$ i.d.) (J \& W Scientific, USA) fused silica capillary column with a $0.25 \mu \mathrm{m}$ film thickness was used with helium as carrier gas (purity $>99.9997$ vol\% and flow rate $=$ $1.1 \mathrm{~mL} / \mathrm{min})$. Oven temperature program was started at $60^{\circ} \mathrm{C}$ (not held) and linear temperature gradient was applied at rate of $3^{\circ} \mathrm{C} / \mathrm{min}$ to final temperature of $260^{\circ} \mathrm{C}$ and held for 5 minutes (total run time: $65 \mathrm{~min}$ ). The ion source temperature was kept at $230^{\circ} \mathrm{C}$, the quadrupole was at $150^{\circ} \mathrm{C}$, and the mass spectra were obtained in 50 to $500 \mathrm{~m} / \mathrm{z}$ range, at an electron energy of $70 \mathrm{eV}$.

ChemStation software (Agilent Technologies) was used for data analysis, and curves used for experimental estimation of retention indices were plotted and drawn using SciDaVis (http://scidavis.sourceforge.net/) software. The identification of the compounds was based on comparison of their retention indices (RI) calculated against mixture of n-alkanes, their retention times (RT), and mass spectra with NIST 05/Adams libraries spectra and literature [19].

2.4. Statistical Analysis. The means of two replicates were subjected to PCA and HCA using XLSTAT (Addinsoft, 2013, NY, USA).

\section{Results and Discussion}

The obtained results of the volatile compounds determination are shown in Table 1. All the results are shown as relative $\%$ of chromatographic peak abundance in total ion chromatograms. Temperature at which samples were analyzed $\left(90^{\circ} \mathrm{C}\right)$ was chosen by the authors in order to represent conditions of the thermal treatment during cooking. The results show that unbranched alkanes represent the main group of volatile compounds in these species. It has been shown that hydrocarbon production in cyanobacteria is mainly achieved by metabolic pathways connected with fatty acids. Research has identified two enzyme families that are responsible for alkane production in cyanobacteria: an acyl-acyl carrier protein reductase (AAR) and an aldehyde decarbonylase (AAD), which play crucial role in converting fatty acid intermediates to alkanes and alkenes [20]. Heptadecane is shown to be present in all of the analyzed samples, with its content ranging from $27.39 \%$ in $\mathrm{C} 5+\mathrm{N}$ sample to $82.21 \%$ in $\mathrm{S} 1$. Hexadecane and pentadecane were also detected in all samples, although in lower amounts compared to heptadecane (0.90$5.45 \%$ for hexadecane and $0.22-8.81 \%$ for pentadecane). Tetradecane and 6,9-heptadecadiene were detected only in samples of Spirulina. Other significant hydrocarbons were 8heptadecene which was detected in one Nostoc (2S9B) and two Anabaena (C2 and C5) strains and 8-methylheptadecane which was detected in 2S7B and C2 strains. 3-Octadecene was detected only in one (2S9B) Nostoc strain. The obtained results are in accordance with work of other authors [21, 22], indicating that, although $\mathrm{C} 16$ and $\mathrm{C} 18$ are the most abundant types of fatty acids in cyanobacteria, the main hydrocarbons produced are from $\mathrm{C} 15$ to $\mathrm{C} 17$ chain length. It should be noted, however, that higher chain hydrocarbons may also be present in the investigated samples but were not detected due to relatively low temperature used during the headspace sampling procedure and not utilizing previous extraction of samples with organic solvents.

2-Methylisoborneol (MIB) and geosmin are among the most important odorous compounds in cyanobacteria and are often cited as sources of unpleasant earth-like and 


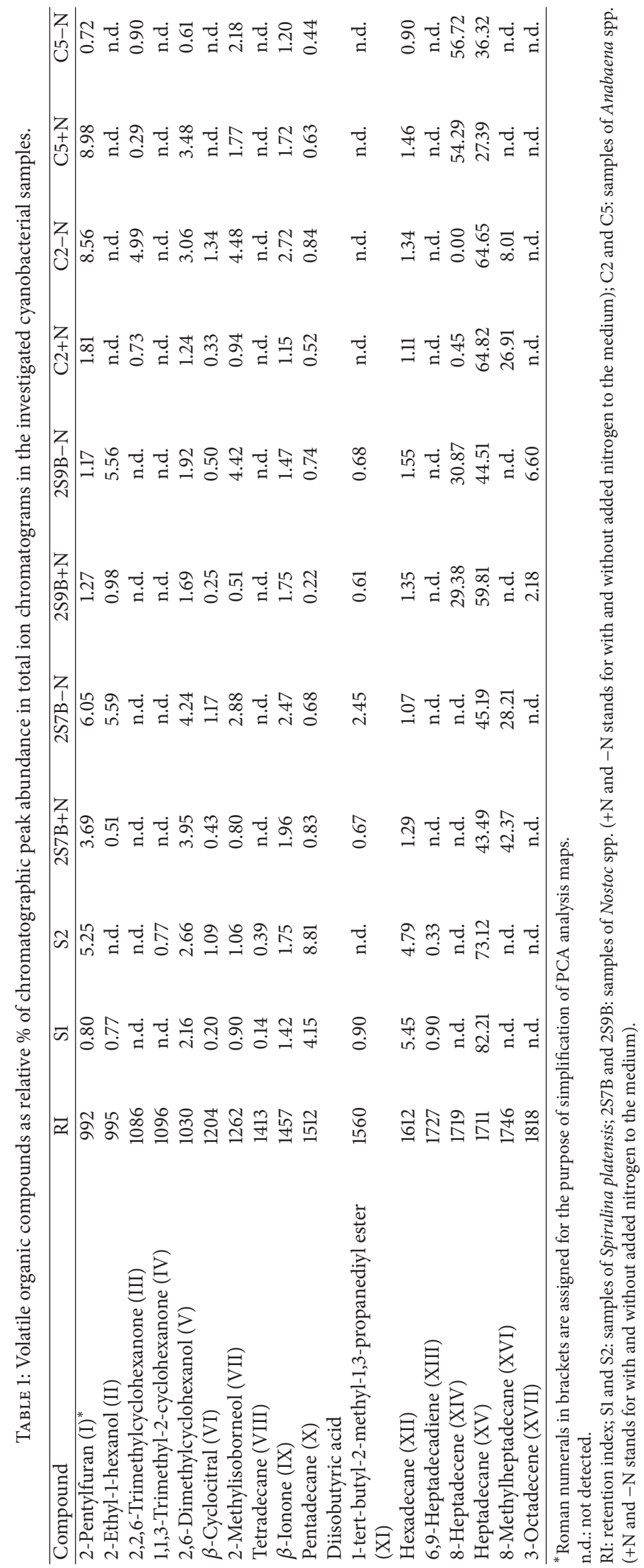


musty odour, especially in various aquatic environments [2325]. MIB was detected in all samples in the range from $0.51 \%$ in sample $2 \mathrm{~S} 9 \mathrm{~B}+\mathrm{N}$ to $4.48 \%$ in sample $\mathrm{C} 2-\mathrm{N}$. It is important to note that, to our knowledge, there have been no previous reports of MIB production by Spirulina species. Concentrations of MIB seem to be higher in all Anabaena and Nostoc strains grown without added nitrogen $(-\mathrm{N})$ when compared to the same strains where nitrogen was added to the growing medium $(+\mathrm{N})$, which may indicate that the presence of added nitrogen suppresses biosynthesis of MIB. The results of increases or decreases in MIB production related to the amount of nitrogen in the growth medium are weakened by relying solely on relative $\%$ of chromatographic peak abundance, since changes in the amounts of other peak areas can directly affect the \% of MIB peak abundance. Regarding this issue, further studies, using MIB standard in order to more accurately quantitate the differences in concentrations in samples, should be undertaken to assess the observed differences. Interestingly, geosmin was not detected in any of the tested samples in this work, which may be explained by observations of Saadoun et al. [24], who concluded that addition of copper ions to growing medium at level above $6.92 \mathrm{mg} \mathrm{Cu}^{2+} / \mathrm{L}$ had inhibitory effect on the production of geosmin. Since copper ions were added to the growing medium of all tested strains in our work in concentrations which were higher than previously mentioned, it may explain why geosmin was not detected in any of the investigated samples. However, it is also possible that none of the cyanobacterial strains in this study naturally produces geosmin. Also, the previously mentioned group of authors had similar observations regarding the effect of added nitrogen to the medium on production of geosmin but, to our knowledge, a similar effect was not previously investigated concerning the levels of MIB.

2-Pentylfuran is a volatile organic compound which is an important product of lipid degradation and is responsible for licorice-like and beany sensory attributes in various food products [26]. It was detected in all samples in concentrations from $0.72 \%$ to $8.98 \%$. $\beta$-Cyclocitral and $\beta$-ionone can also be considered as important volatile odour compounds and are commonly used in food industry as components of artificial flavourings. $\beta$-Ionone was detected in all the investigated strains of cyanobacteria in relatively high concentration range (1.15-2.72\%), while $\beta$-cyclocitral was also detected in all samples, except in C5 strain of Anabaena, however, in lower amounts (0.20-1.34\%). $\beta$-Cyclocitral, known to be produced by Microcystis cyanobacterial strains, is a product of enzymatic degradation of $\beta$-carotene, and its presence can indicate death of cyanobacterial cells [25]. Although the analyzed samples were previously lyophilized, they were considered biologically viable after rehydratation. The detected levels of $\beta$-cyclocitral may indicate that the applied thermal treatment of such cells causes cell damage and degradation of $\beta$-carotene.

Principal component analysis (PCA) and hierarchical cluster analysis (HCA) are among the most popular multivariate explanatory methods used to reduce number of parameters retaining only those which are the most

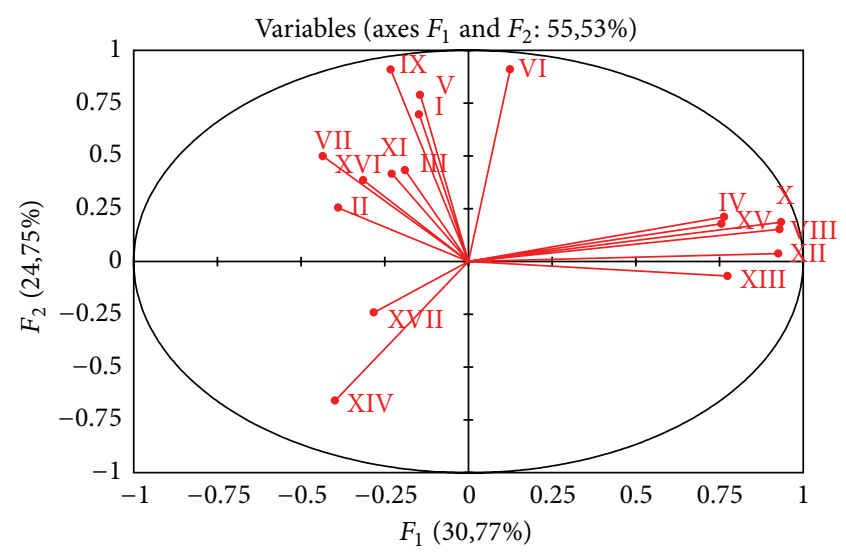

FIGURE 1: PCA: projection of the variables on the factor plane.

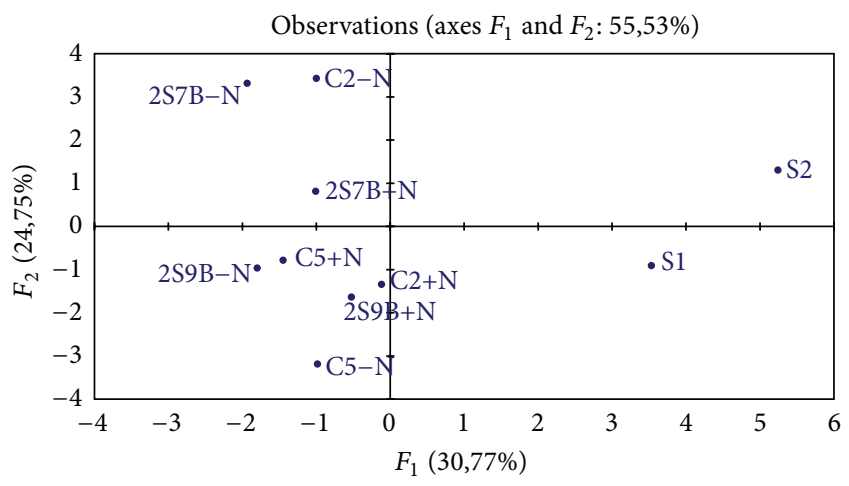

FIGURE 2: PCA: projection of the cases on the factor plane.

significant for the explanation of some phenomena. These two techniques complement one another and have been widely used in solving classification problems [27]. The data matrix constructed of 10 rows (investigated samples) and 17 columns (volatile compounds) was subjected to PCA analysis. The first two components explained $55.53 \%$ of variance, with component $\mathrm{PC1}$ contributing $30.77 \%$ and component PC2 24.75\%.

The first plot (Figure 1) shows a projection of the initial variables in the factor space. The horizontal axis (PC1) is related with hydrocarbons of alkane and alkene type (with an exception of compound IV) since it is highly correlated with compounds IV, VIII, X, XII, XIII, and XV. The second, vertical axis is well linked with compounds I, V, VI, and IX, which are of cyclic or bicyclic structure. Compound XIV (8-heptadecene) is on the opposite side of the centre, implying that it is negatively correlated with PC2 axis, correctly indicating that this compound does not possess cyclic structure.

The algae samples were completely separated by the determined organic compounds (Figure 2). Samples of Spirulina, labeled as S1 and S2, are quite unique and can be distinguished mostly by their content of alkanes, while Anabaena and Nostoc samples labeled as $\mathrm{C} 2-\mathrm{N}$ and $2 \mathrm{~S} 7 \mathrm{~B}-\mathrm{N}$ were separated mostly by high concentration of compounds V, VI, and 


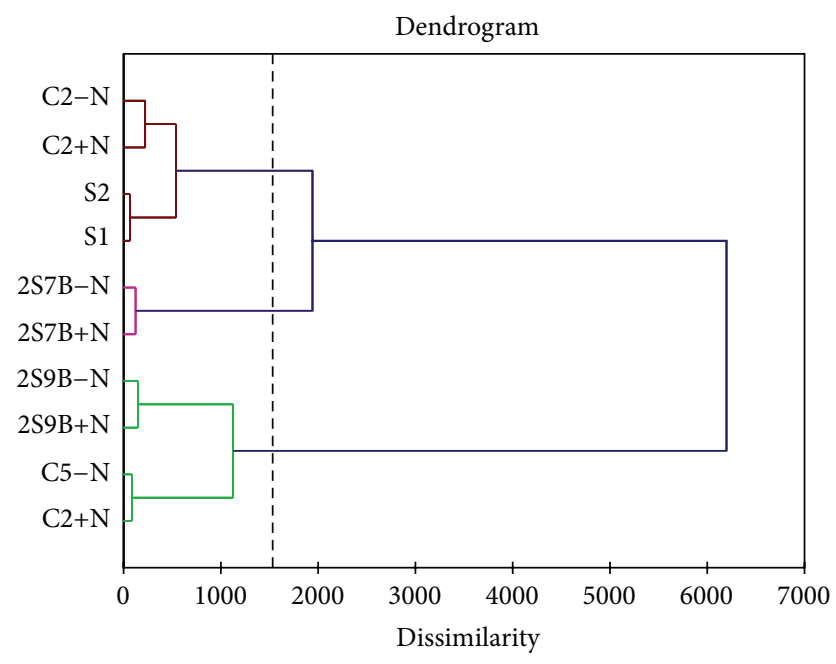

Figure 3: Dendrogram for the HCA results using Ward's clustering algorithm.

IX (2,6-dimethyl-cyclohexanol, $\beta$-cyclocitral, and $\beta$-ionone, resp.).

According to these graphs, we can assume that samples can be categorized in three or four different groups. But for the purpose of more detailed determination of similarities between samples, data are subjected to a hierarchical cluster analysis (HCA). Figure 3 shows the horizontal hierarchical tree plot, called dendrogram, for the cluster analysis results using Ward's algorithm. All samples are divided into three separate groups. First and third clusters contain four samples and the second only two. Dendrogram shows that the samples constituting first two groups are more homogenous than in the third one. The results are confirmed by variance within the class, for Cluster 1: 274.11, Cluster 2: 121.62, and Cluster 3: 452.66. It appears that S1 and S2 Spirulina samples are very similar to $\mathrm{C} 2$ strains of Anabaena $(\mathrm{C} 2-\mathrm{N}$ and $\mathrm{C} 2+\mathrm{N})$ and, going back to Table 1 , it can be noticed that similarity is derived from the lack of 8-heptadecene and 3-octadecene in these samples.

\section{Conclusion}

The obtained results of the volatile compounds determination show that medium length alkanes and alkenes represent the main volatile components of the investigated strains of cyanobacteria. Presence of odorous compounds such as 2-methylisoborneol, 2-pentylfuran, $\beta$-cyclocitral, and $\beta$ ionone was also observed in the samples in various concentrations. Content of 2-methylisoborneol was lower in samples which were grown in medium with higher added nitrogen levels, although further studies using standard of 2-methylisoborneol should be undertaken to more precisely assess the observed differences. Presence of geosmin, which is very important component of odour, was not detected in any of the tested samples, which may be explained by the presence of relatively high concentrations of copper ions to the growth medium. Principal component analysis (PCA) and hierarchical cluster analysis (HCA) have shown good separation of analyzed samples regarding the type and concentration of their volatile compounds and samples of Spirulina were characterized as notably different from other cyanobacterial strains with regard to their high content of alkanes. It can also be concluded that growing conditions have significant impact on production of volatile and odorous compounds in cyanobacteria, and altering these conditions may be useful in obtaining cyanobacterial biomass with favorable sensory properties for potential use in formulation of food and feed products.

\section{Conflict of Interests}

The authors declare that there is no conflict of interests regarding the publication of this paper.

\section{Acknowledgment}

This paper is a result of the research within the Technological Development Project (TR-31029) supported by the Ministry of Education and Science, Serbia.

\section{References}

[1] J. Fehling, D. K. Stoecker, and S. L. Baldauf, "Photosynthesis and the eukaryote tree of life," in Evolution of Primary Producers in the Sea, P. G. Falkowski and A. H. Knoll, Eds., pp. 75-107, Academic Press, New York, NY, USA, 2007.

[2] R. F. Stern, A. Horak, R. L. Andrew et al., "Environmental barcoding reveals massive dinoflagellate diversity in marine environments," PLoS ONE, vol. 5, no. 11, Article ID e13991, 2010.

[3] M. A. Borowitzka, "High-value products from microalgaetheir development and commercialisation," Journal of Applied Phycology, vol. 25, no. 3, pp. 743-756, 2013.

[4] M. A. Borowitzka, "Carotenoid production using microorganisms," in Single Cell Oils: Microbial and Algal Oils, Z. Cohen and C. Ratledge, Eds., pp. 225-240, AOCS Press, Urbana, Ill, USA, 2010.

[5] A. Mendes, A. Reis, R. Vasconcelos, P. Guerra, and T. Lopes Da Silva, "Crypthecodinium cohnii with emphasis on DHA production: a review," Journal of Applied Phycology, vol. 21, no. 2, pp. 199-214, 2009.

[6] D. J. Kovač, J. B. Simeunović, O. B. Babić, A. Č. Mišan, and I. L. Milovanović, "Algae in food and feed," Food \& Feed Research, vol. 40, no. 1, pp. 21-31, 2013.

[7] S. Singh, B. N. Kate, and U. C. Banecjee, "Bioactive compounds from cyanobacteria and microalgae: an overview," Critical Reviews in Biotechnology, vol. 25, no. 3, pp. 73-95, 2005.

[8] J. Simeunović, K. Bešlin, Z. Svirčev, D. Kovač, and O. Babić, "Impact of nitrogen and drought on phycobiliprotein content in terrestrial cyanobacterial strains," Journal of Applied Phycology, vol. 25, no. 2, pp. 597-607, 2013.

[9] J. Simeunović, S. Marković, D. Kovač, A. Mišan, A. Mandić, and Z. Svirčev, "Filamentous cyanobacteria from Vojvodina region as source of phycobiliprotein pigments as potential natural colorants," Food \& Feed Research, vol. 39, no. 1, pp. 23-31, 2012.

[10] A. P. Batista, L. Gouveia, N. M. Bandarra, J. M. Franco, and A. Raymundo, "Comparison of microalgal biomass profiles as novel functional ingredient for food products," Algal Research, vol. 2, no. 2, pp. 164-173, 2013. 
[11] J. L. Smith, G. L. Boyer, and P. V. Zimba, "A review of cyanobacterial odorous and bioactive metabolites: impacts and management alternatives in aquaculture," Aquaculture, vol. 280, no. 1-4, pp. 5-20, 2008.

[12] M. Fradique, A. P. Batista, M. C. Nunes, L. Gouveia, N. M. Bandarra, and A. Raymundo, "Isochrysis galbana and Diacronema vlkianum biomass incorporation in pasta products as PUFA's source," LWT-Food Science and Technology, vol. 50, no. 1, pp. 312-319, 2013.

[13] P. E. Persson, "Sensory properties and analysis of two muddy odour compounds, geosmin and 2-methylisoborneol, in water and fish," Water Research, vol. 14, no. 8, pp. 1113-1118, 1980.

[14] D. Kovač, O. Babić, J. Simeunović, and K. Tešanović, “The influence of nitrogen on the production of toxic and antibacterial substances in cyanobacteria," in Proceedings of the 9th European Workshop on the Molecular Biology of Cyanobacteria, Abstract Book, p. 152, Texel, The Netherlands, 2014.

[15] I. Milovanović, A. Mišan, B. Šarić et al., "Evaluation of protein and lipid content and determination of fatty acid profile in selected species of cyanobacteria," in Proceedings of the 6th Central European Congress on Food (Cefood '12), pp. 13-17, Novi Sad, Serbia, 2012.

[16] J. Simeunović, Cyanobacterial Culture Collection (in Serbian: Kolekcija kultura cijanobakterija), Biblioteka Academia Zadužbina Andrejević, Belgrade, Serbia, 2005.

[17] R. Rippka, J. Deruelles, and J. B. Waterbury, "Generic assignments, strain histories and properties of pure cultures of cyanobacteria," Journal of General Microbiology, vol. 111, no. 1, pp. 1-61, 1979.

[18] P. Soong, "Production and development of Chlorella and Spirulina in Taiwan," in Algae Biomass, G. Shelef and C. J. Soeder, Eds., pp. 97-115, Elsevier/North-Holland, Biomedical Press, 1980.

[19] R. P. Adams, Identification of Essential Oil Components by Gas Chromatography/Mass Spectroscopy, Allured, Carol Stream, Ill, USA, 1995.

[20] D. C. Ducat, J. C. Way, and P. A. Silver, "Engineering cyanobacteria to generate high-value products," Trends in Biotechnology, vol. 29, no. 2, pp. 95-103, 2011.

[21] G. Ozdemir, N. U. Karabay, M. C. Dalay, and B. Pazarbasi, "Antibacterial activity of volatile component and various extracts of Spirulina platensis," Phytotherapy Research, vol. 18, no. 9, pp. 754-757, 2004.

[22] A. Liu, T. Zhu, X. Lu, and L. Song, "Hydrocarbon profiles and phylogenetic analyses of diversified cyanobacterial species," Applied Energy, vol. 111, pp. 383-393, 2013.

[23] N. Sugiura, N. Iwami, Y. Inamori, O. Nishimura, and R. Sudo, "Significance of attached cyanobacteria relevant to the occurrence of musty odor in Lake Kasumigaura," Water Research, vol. 32, no. 12, pp. 3549-3554, 1998.

[24] I. M. K. Saadoun, K. K. Schrader, and W. T. Blevins, "Environmental and nutritional factors affecting geosmin synthesis by Anabaena sp," Water Research, vol. 35, no. 5, pp. 1209-1218, 2001.

[25] D. Fujise, K. Tsuji, N. Fukushima, K. Kawai, and K.-I. Harada, "Analytical aspects of cyanobacterial volatile organic compounds for investigation of their production behavior," Journal of Chromatography A, vol. 1217, no. 39, pp. 6122-6125, 2010.

[26] H. S. Lam and A. Proctor, "Milled rice oxidation volatiles and odor development," Journal of Food Science, vol. 68, no. 9, pp. 2676-2681, 2003.
[27] G. Ragno, M. D. Luca, and G. Ioele, "An application of cluster analysis and multivariate classification methods to spring water monitoring data," Microchemical Journal, vol. 87, no. 2, pp. 119127, 2007. 

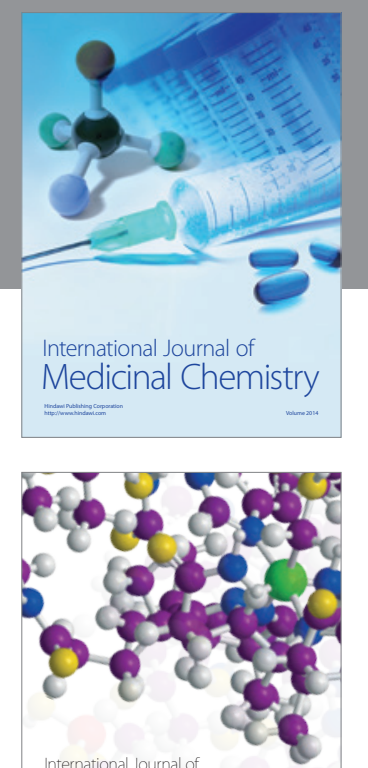

\section{Carbohydrate} Chemistry

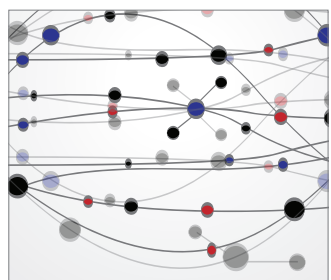

The Scientific World Journal
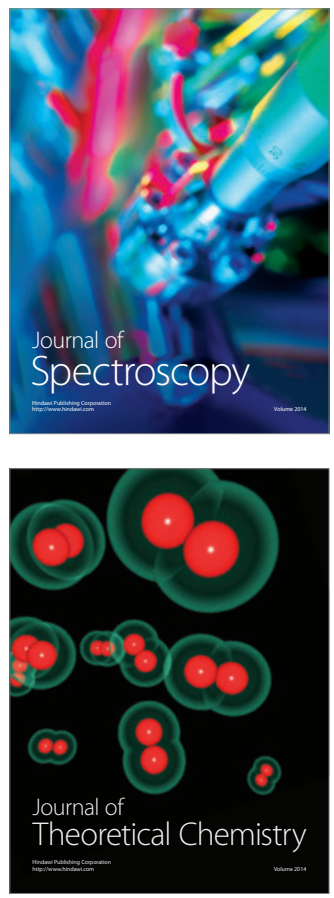
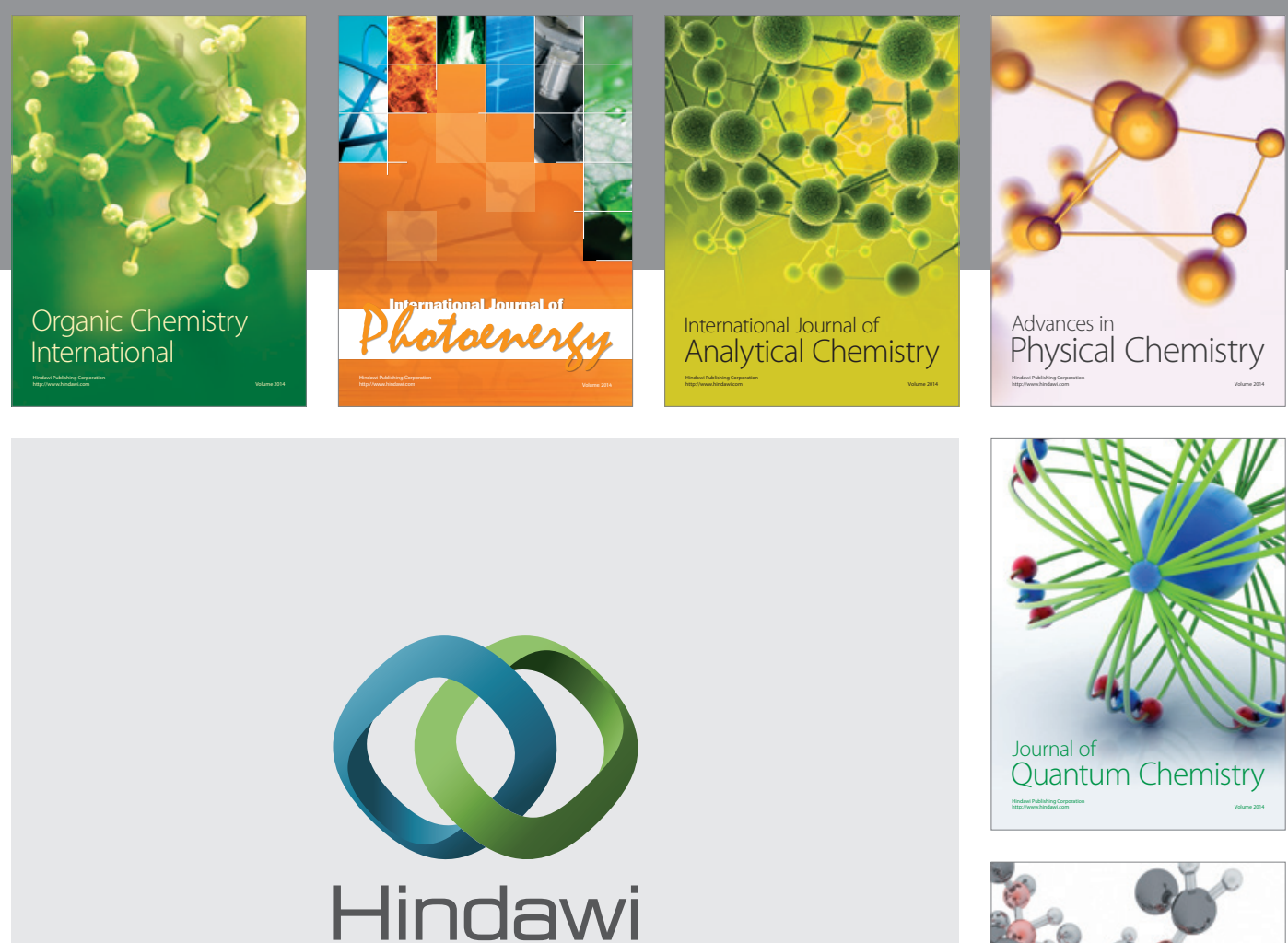

Submit your manuscripts at

http://www.hindawi.com

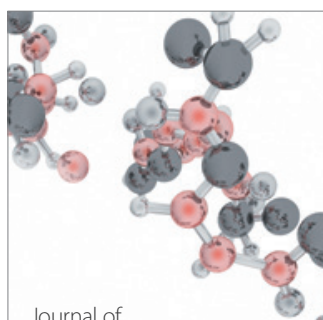

Analytical Methods

in Chemistry

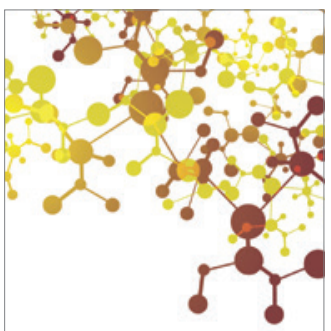

Journal of

Applied Chemistry

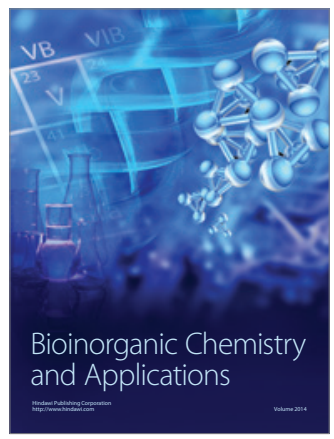

Inorganic Chemistry
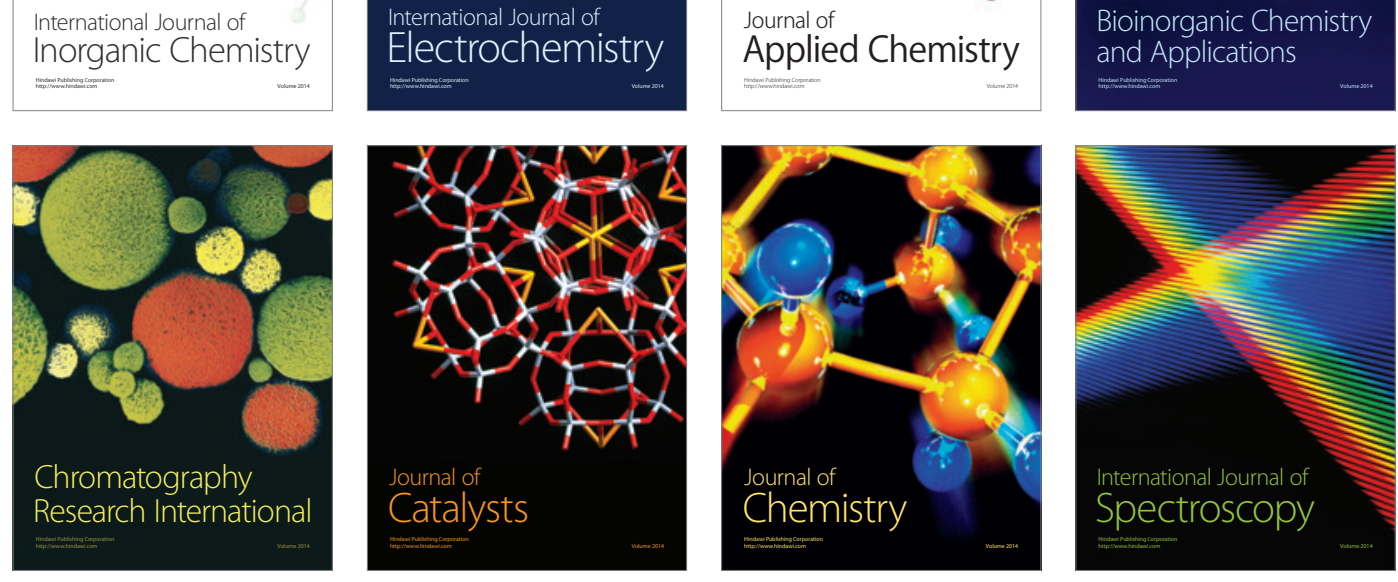